\title{
Center for Economic Development, Innovation, and Commercialization: A Pathway for Economic Sustainability from Research and Application to Enterprise
}

Ron Kessler and Pike Powers

\section{Introduction}

\section{Robert Barnhill}

Vice Chancellor for Research and Technology Transfer, University of Texas System Board member, Merrill Advanced Studies Center

$\mathrm{E}$ ach year, participants in the Merrill Center Research Policy seminars have taken up a timely topic, this year's being "The Interface of Science and Public Policy." There are new national and international trends in science, some of which Alan Leshner has already covered, such as an increase in "big" science and in the sense of larger problems being addressed by teams of people. Such problems require multidisciplinary approaches as well as new kinds of leadership.

From the beginning, these Merrill Center conferences have brought together the university leadership from what I have called the "Midwestern four-corner" states of Kansas, Missouri, Iowa, and Nebraska. (Both as the senior research officer, formerly, at The University of Kansas and as a Lawrence, Kansas, native, I have enjoyed seeing five of the Big 7-or Big 8-work together.) Many research and research policy collaborations have begun, both directly and indirectly, as a result of these meetings.

Now we are ready to consider a next geographical step for research and its societal utility to encompass the Big 12 conference. The Big 12 extends over seven states in the heartland of the nation; the communities have some commonalities, such as water sources and geography, and some differences, such as populations and growth patterns.

Texas generally and Austin in particular have the well deserved

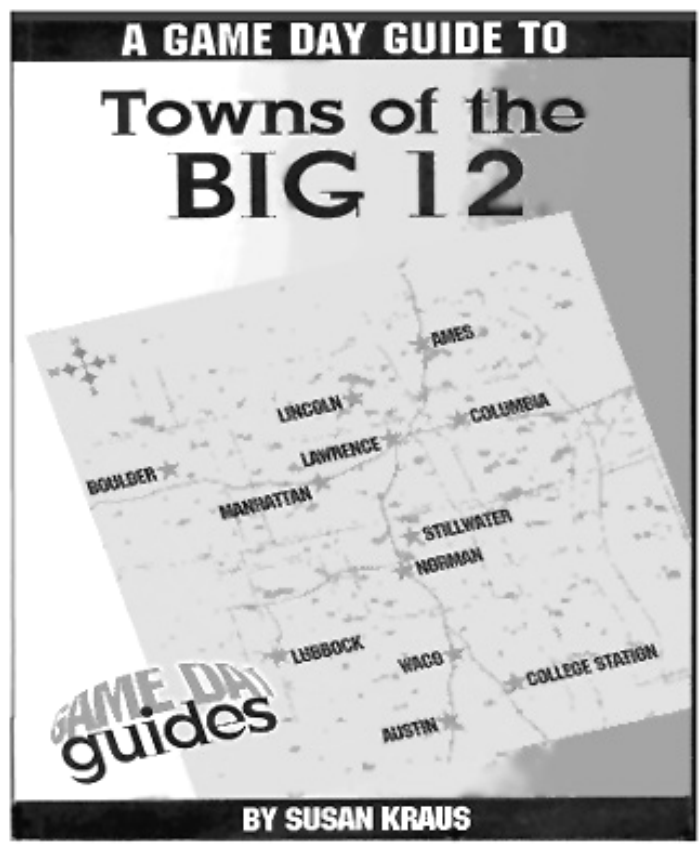


reputations of encouraging economic encouraged various countermeasures. One was the formation of Sematech in Austin, which helped turn that particular tide. Among the key architects of this novel development were Pike Powers and Ron Kessler. Pike and Ron are now proposing to bring the ideas of the "Austin miracle" to the Big 12 universities and their communities.

They find inspiration in the statement of Irving Wladawsky-Berger, of IBM: "This emerging era is characterized by the collaborative innovation of many people working in gifted communities, just as innovation in the industrial era was characterized by individual genius." 1

At the 2001 Merrill Center meeting on "Evaluating Research Productivity" I paraphrased the theme from Competing

\footnotetext{
${ }^{1}$ Dr. Irving Wladawsky-Berger, vice president for technology \& strategy at IBM, quoted in The World is Flat, Thomas L. Friedman, p. 93.
}

entrepreneurial activity. For example, in for the Future as: "Strategic intent by top leadership, coupled with natural advantages and local expertise, can lead to research enhancement that lifts the entire institution." ${ }^{2}$ I cited this in the context of several universities who have so moved forward. Now let us consider multiple universities.

I like to paraphrase the title of the book Only the Paranoid Survive, by Andy Grove of Intel, as "only the flexible thrive." The latter is directly applicable to the Big 12 possibilities envisioned by Powers and Kessler. They suggest that we adopt a flexible approach to multiinstitutional sharing and collaboration the areas of research and its societal impact. Their description of this project follows.

\footnotetext{
${ }^{2}$ Gary Hamel and C. K. Prahalad, Competing for the Future, p. 29.
} 


\section{Center for Economic Development, Innovation, and Commercialization}

\section{By Ron Kessler and Pike Powers}

The purpose of the Big 12 Center for Economic Development, Innovation, and Commercialization (CEDIC) is to develop, foster, and nurture more collaborative and mutually beneficial activities within and among the 12 universities, and to facilitate the flow of innovation, commercialization, entrepreneurship, and "know-how" from the universities to the private sector, thereby creating jobs and enhancing the wellbeing of the citizens of each university's state and region. As a result, the collective assets and resources of the 12 university, seven-state region are effectively leveraged in ways and with benefits that no one university can achieve.

Intending to accelerate economic growth and intellectual excellence through collaboration, the Big 12 CEDIC has already created momentum and important support. The 12 universities individually and their seven home states have benefited significantly from collaborating in the Big 12 Conference. This athletic success will be extended and enhanced by addressing the significant issues facing each state and university through the Big 12 CEDIC.

Our approach involves five areas: collaboration, competition, celebration, communication, and capital.

- Collaboration will involve both joint Research to address common problems and coordinated Commercialization efforts to take university developed technologies to market.
- Competition will include both graduate and undergraduate student competitions to address common problems and provide experiential learning.

- Celebration will recognize, publicize and celebrate our outstanding business leaders, researchers and faculty.

- Communication will involve a coordinated media and publicity plan to communicate the activities, successes and excitement of the Big 12 CEDIC. This area also includes grant writing activity and corporate sponsor solicitation.

- Capital will involve the creation of university affinity funds and a Big 12 Fund of Funds and bringing together $\mathrm{VC}^{\prime}$ 's and other capital providers.

Initiatives in each of these five areas will begin on October 1, 2005, and longer term initiatives will be launched over the next six months. After meeting and developing relationships with KTEC, the Kauffman Foundation, the Kansas City Federal Reserve Bank, Department of Commerce (EDA), RUPRI, LCRA, SBC, SAIC, IBM and various Chambers of

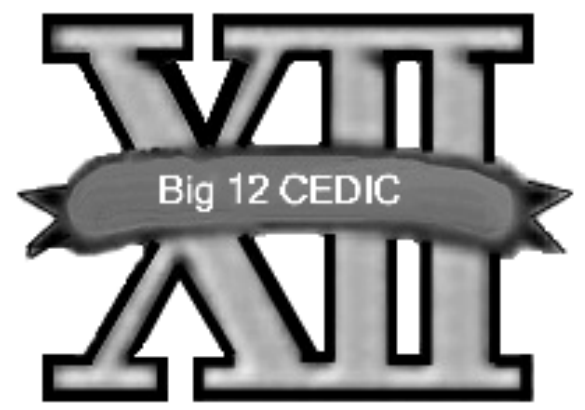


Commerce, we are ready to launch the Big 12 CEDIC.

We have found significant interest among the private, foundation, and government sectors and from economic development entities for this innovative approach. Potential corporate sponsors, venture capitalists, and other capital providers realize that they will be introduced to the best that these universities, individually and collectively, have to offer-the most innovative ideas, the finest and best prepared students, attractive host communities and a collaborative environment. Equally important, we have also received enthusiastic responses from Big 12 Vice Provosts for Research (VPR), Deans, and faculty members. As a result, meetings of VPRs and Engineering Deans are the first planned.

We have asked the school presidents and/or chancellors to sign a Big 12 CEDIC Charter to acknowledge their commitment to our seven-state region and to commit their universities to addressing the economic needs of the region and collaborating on increasing funding for research. This innovative concept has significant power. It will attract attention and increased research dollars, as well as position the Big 12 in an even more favorable light and in a national leadership position. Collectively, the 12 universities will create more opportunities for excellence than any one university acting alone.

We will collaborate outside the universities to leverage the various economic development, workforce training, and capital providers for a focused seven-state regional economic development network.

The universities of the Big 12 have a tremendous opportunity to move beyond their past successes and to fulfill the significant role that the university plays in today's economy. This Big 12 collaboration serves to take these universities to a new level of excellence with increased prospects for additional funding sources and contributions to regional and local economies. Over the next decade the Big 12 universities will build capacity that leverages their unique assets, collaborate with other universities, and achieve an alignment with each university's mission of instruction, research and outreach. Maximum potential for good for society occurs at the intersection of the university, the private sector, the foundation sector, and the government sector as each looks for strategic alliances that improve the quality of life for the people of their region and state. No other athletic conference has attempted such a collaboration. The Big 12 doing it first and doing it well will set the "gold standard" for athletic conferences, economic development, innovation, and commercialization. 


\section{UNIVERSITY $\times 12+$ STATE $\times 7 \times$ COLLABORATION $=$ "LEVERAGES"}

Economic development - blocking and tackling - must have many sources of funding to create a focused common ground:

\section{CAPCO(s) or similar ventures \\ VC Funds}

Tech Transfer

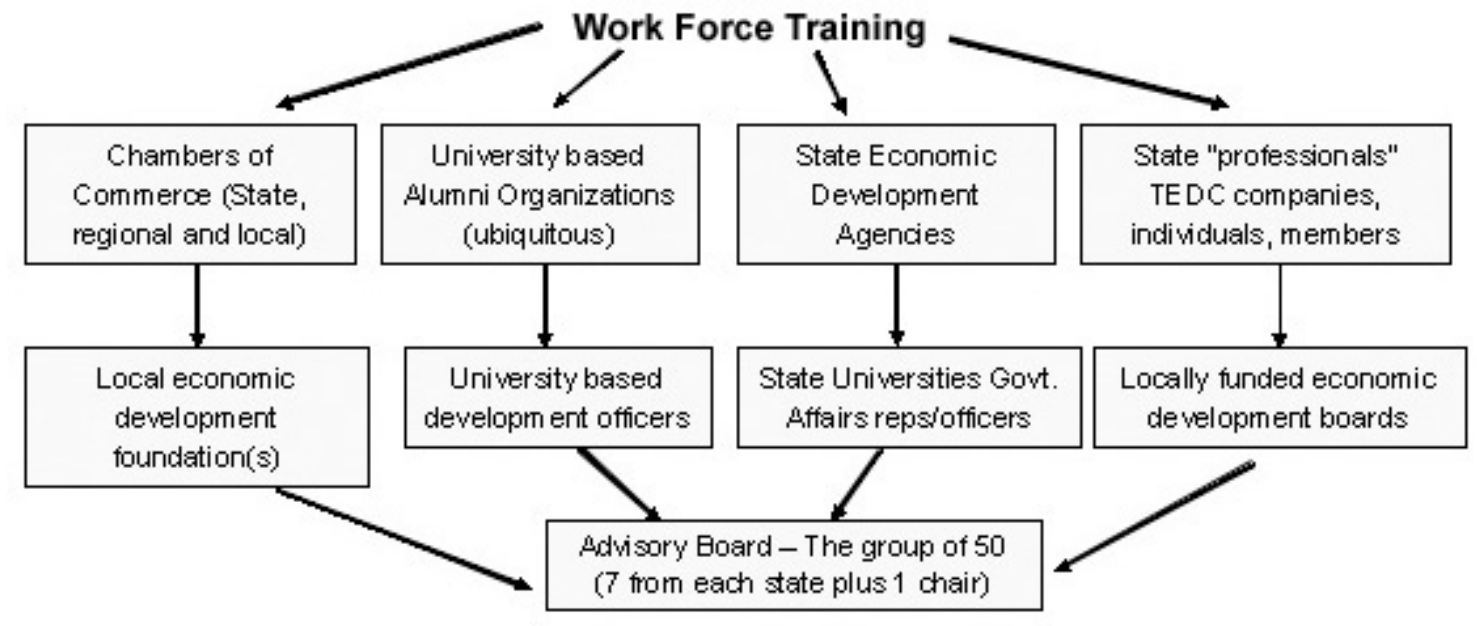

\section{Brought together by common ground and the love of sports.}

Creates BIG 12 "Network of Networks"

for a focused seven-state regional economic development network

convened in Fall to brief on first six programs;

Provides local muscle in public launch shortly thereafter.

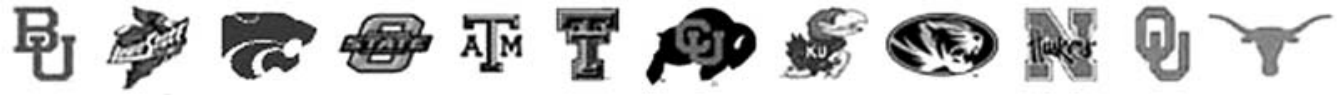

Most of the world's really smart people aren't members of any single team but are distributed all over the place in multiple institutions. Similarly , we are now looking for innovations in the interstices between different disciplines_-for example, between bio- and nanotechnologies.

-John Seely Brown 